\title{
Assess the Radiological Change of Post Extraction Socket after Using Beta Tricalcium Phosphate for Understanding of Bone Formation
}

\author{
Dr. Muhammad Mubashirul Haque ${ }^{1 *}$, Dr. Mostafa Md. Anisuzzaman ${ }^{2}$, Dr. Sajid Hasan ${ }^{3}$, Dr. Nubad Adnan ${ }^{4}$
}

\author{
${ }^{1}$ Assistant Professor, Department of Periodontology and Oral Pathology, Birdem General Hospital, Dhaka, Bangladesh \\ ${ }^{2}$ Lecturer, Department of Oral and Maxillofacial Surgery, Ibrahim Medical College (Dental unit), Dhaka, Bangladesh \\ ${ }^{3}$ Assistant Professor, Department of Oral and Maxillofacial Surgery, Ibrahim Medical College (Dental unit), Dhaka, Bangladesh \\ ${ }^{4}$ Medical Officer, Department of Dental Surgery, Birdem General Hospital, Dhaka, Bangladesh
}

DOI: $\underline{10.36347 / \text { sjds.2021.v08i05.006 }}$

| Received: 04.02.2021 | Accepted: 09.04.2021 | Published: 17.06.2021

*Corresponding author: Dr. Muhammad Mubashirul Haque

Abstract

Original Research Article

Background: Bone healing is an important subject in various fields of dentistry such as prosthesis, implant, surgery, etc. Numerous studies and researches have been done on tooth socket healing process however, most of these studies are histological evaluations and less are radiographic studies. Aim: The aim the Study was the Radiological Change of Post Extraction Socket after Using Beta Tricalcium Phosphate for Understanding of Bone Formation. Methods: The experimental Study was conducted in the department of oral and maxillofacial of in Bangabandhu Sheikh Mujib Medical University Hospital (BSMMU), Dhaka, Bangladesh to find out the common indications of Post Extraction Socket. 20 patients (Group-A) whose full veneer crown were prepared on Alloplastic bone substitute and another 20 patients (Group-B) whose were without alloplastic bone substitute. 40 cases were randomly selected for the study whose common indication of Radiological Change of Post Extraction Socket after Using Beta Tricalcium Phosphate. Clinical examination and evaluation were done from October 2010 to February 2011. Other necessary investigations were done if clinically indicated and to prepare the patient for anesthesia. Statistical analysis of the results was obtained by using window-based computer software devised with Statistical Packages for Social Sciences (SPSS-22). Results: Table shows the distribution of the age of the patients. Majority of the patients 22(55.0\%) were of 18-25 years age group and another 15(37.5\%) were at their 26-35 age group. Mean age of the patients was 25.97 \pm 4.99 years. Conclusion: Both QDSR and LRA methods can be used in evaluation of the rate of bone formation in the tooth socket but the former method is more accurate.

Keywords: Mandibular third molars; Bone regeneration; $\beta$-tricalcium phosphate; Calcium sulfate; Bone gain.

Copyright $\odot 2021$ The Author(s): This is an open-access article distributed under the terms of the Creative Commons Attribution 4.0 International License (CC BY-NC 4.0) which permits unrestricted use, distribution, and reproduction in any medium for non-commercial use provided the original author and source are credited.

\section{INTRODUCTION}

Bone grafting procedure was first described by Dutch Surgeon Job Van Meekeren in 1668. In 1674, Van Leeuwenhoek, Dutch scientist, gave the idea of bone grafting and bone structure. He found several little holes over bone passing form without inwards. Todays these pipes are known as Haversian canals [1]. In 1880, by William Macewen from Scotland perform the first allograft and published a description of the proceeding of the Royal Society of London in 1881[1]. The first clinical application of calcium phosphate entailed the successful repair of bony defect by Albee in 1920 [2]. Zerbo and coworkers reported that the use of beta TCP granules for the treatment of bone defects, which resulted from cyst enucleation. At 9.5 months, remnants of granules were found in close a histological analysis. No signs of inflammation contact with new formed bone in were observed. From the report, it was concluded that beta - TCP granules were infective in the treatment of large bone defects that result from cystectomy [3]. Palm and coworkers assessed the capacity of beta - TCP to stimulate russification of 64 defects that resulted from cystectomy in 63 patients. They found that new bone formation dependent on the defect size. After 9 months, even the largest lesions with diameter of more than $2.5 \mathrm{~cm}$, beta - TCP has been replaced by newly formed bone as judged from radiographs [4]. Palti reported the treatment of lesions after apicoectomy, cystectomy and the treatment of alveolar bone defects of beta - TCP granules. No complications were observed in $97.8 \%$ of 958 treatments of the Dental bone defects with beta - TCP [6]. The application of beta - TCP as a bone substitute in 152 patients was reported by Hoch and colleagues. Beta - TCP was used to fill large mandibular cysts for secondary tertiary alveolar plate grafting, to fill periodontal defects and for maxillary sinus floor 
Muhammad Mubashirul Haque et al., Sch J Dent Sci, Jun, 2021; 8(5): 153-159

augmentation. Complete replacement of beta _ TCP by autologous bone was detected after approximately 12 months, histological analysis in 16 biopsied cases showed a complete bony regeneration. Partial loss of the bone substitute material occurred in $5.9 \%$ of the patients whereas a total loss of beta - TCP graft was found in only $2 \%$ of the cases. The authors conclude that synthetic, phase aure beta - TCP is a suitable material for the treatment of bone defects in the alveolar region [5].

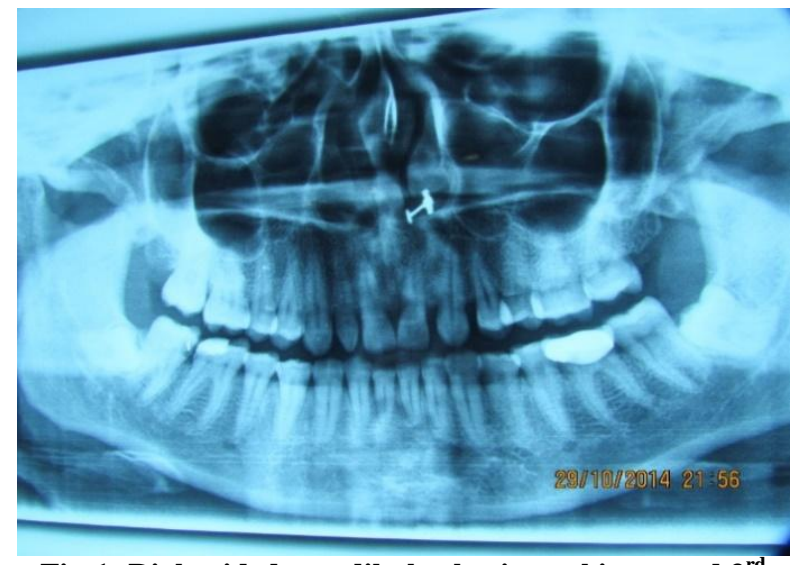

Fig-1: Right sided mandibular horizontal impacted $3^{\text {rd }}$ molar tooth before operation

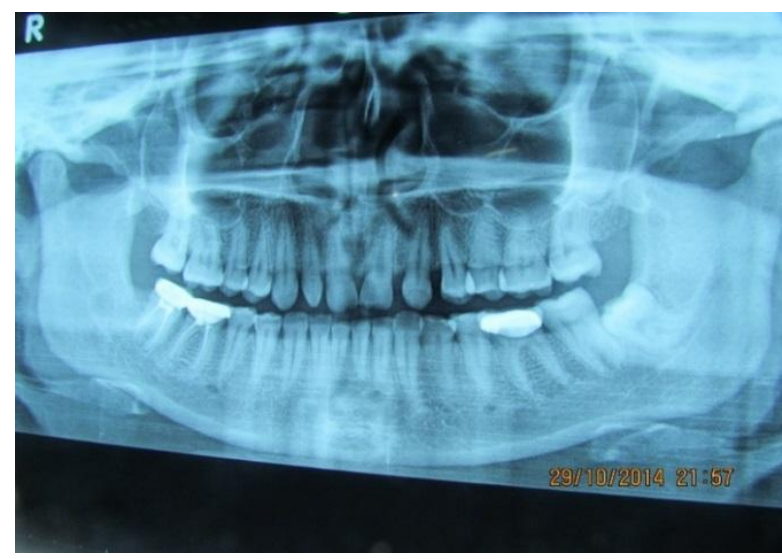

Fig-II: Post extraction socket six months after operation. Significant radiological improvement was observed

Palti and hoch reported a case where the use of beta - TCP permitted a reduce the periodontal pocket depth by $4 \mathrm{~mm}$ at 18 months postoperatively. At this time, beta - TCP granules were completely resorbed as judged from radiographs [6]. Positive results in the treatment of periodontitis with beta - TCP were confirmed in a report with 86 patients. Radiographic imaging showed that the clinical situation improved for most patients over period of 20 months [7]. In another report Foitzik and status point out the deep, solitary periodontal defects are very well suited for treatment with beta TCP granulates and that application of a membrane may be beneficial based on a clinical experience of 4 years [8]. Bokan used a combination of beta - TCP and an enamel matrix derivative (EMD) to treat intrabody periodontal defects in 19 patients. Measurements after
12 months showed that the combination of beta - TCP and EMD leads is to significant clinical improvement reducing probing pocket depth and an increase in the probing attachment level [9]. Reinhardt and Kreusser reported successful sinus floor augmentations using beta - TCP granules in 50 patients. In six cases, complications (sinusitis, thread dehiscence) that could be easily treated with antibiotics were reported. Radiographic images suggested that the beta - TCP granules were resorbed within 6 to 9 months post operatively. Lameller bone was found in a histological analysis from the augmented areas 6 months after the intervention. $99 \%$ of the 101 implants were Osseo integrated after 3, 5 years [10]. Similarly, Kreusser reported sinus floor elevation with beta - TCP and placement of 103 implants in 45 patients. None of the implants were lost and healing was uneventful [11]. Zerbo augmented the sinus floor often edentulous patient with an atrophic maxilla. 8 months postoperatively, the volume of newly formed bone was $20 \%, 44 \%$ of the volume was occupied by beta - TCP granules that were not yet resorbed. Bone and osteoid were found in close contact with remaining granules, histological signs of inflammation were absent. The authors point out that beta - TCP granules are a suitable biodegradable bone substitute [12]. Fussinger reported sinus floor elevation in 17 patients from whom histological samples were taken from the area augmented with beta - TCP. Already after 4 months, bone neogeness was observed around the beta - TCP granules. Mature lamellar bone was seen. After 6 months whereas degradation of beta - TCP granules proceeded along with bone formation. In the same study, the long-term stability of 17 implants that were placed after sinus elevation was $94.4 \%$ in study with 28 patients that were followed for 1.5 to 7 years. Based on their findings, the authors suggest that implants may be placed 4.5 months after sinus elevation [13].

In order to understand osteogenesis and the degradation of beta - TCP in the augmented maxillary sinus floor, Zerbo and coworkers analyzed the localization of cells with osteogenic or osteoclastic potential in relation to the TCP particles in histological samples of 12 patients after 6 months. The findings suggest that bet - TCP particles attract osteoprogenitor cells the migrate into the interconnecting micropores of the bone substitute material. The lack of large multinucleated TRAP (Tartrate Resistant Acid Phosphatase) positive cells suggests that resorption of the beta - TCP material by osteoclasts players' only minor role in the replacement by bone [13].

In a large-scale study, Fugazzotto carried out GBR around 1503 implants using beta - TCP mixed with BFDB. Dehiscent or fenestrated implants and implants that were inserted into immediate extraction sockets were treated. In $97.0 \%$ of all cases, a recovery of the hard tissue was observed demonstrating the potential of GBR [14]. By comparing combinations of the different graft materials in 48 sinus floor elevations, 
Simunek and coworkers found that adding $10 \%$ or $20 \%$ autologous bone to bet - TCP did not result in a significantly increased bone formation compared to beta - TCP alone in the augmentade sinus floor after 9 months. Antoun and coworkers report the use of bovine hydroxyapatite combined with PRP on one side and beta - TCP combined with PRP on the other side of a bilateral sinus floor elevation. The result suggested that both materials are suited for this procedure. Interestingly, lamellar bone was found 6 months after grafting in the beta - TCP but not in the bovine hydroxyapatite graft [15]. Yassibag - Berkman and coworkers treated 30 anterior, intrabody, interproximal lesions in 25 patients either with beta - TCP alone, beta - TCP combined with PRP, and beta - TCP with PRP covered with a collegen membrane in order to assess the clinical gain of PRP in the treatment of periodontal defects. They found that all three options were effective in the treatment of periodontal defects. The use of PRP together with a membrane lead to a higher clinical bone fill after six months compared to beta - TCP or beta TCP/PRP. After 12 months, the difference had disappeared [16].

\section{OBJECTIVE}

The aim the Study was the Radiological Change of Post Extraction Socket after Using Beta Tricalcium Phosphate for Understanding of Bone Formation.

\section{METHODOLOGY}

This experimental study was conducted in Bangabandhu Sheikh Mujib Medical University Hospital (BSMMU), during January 2010 to December 2011. The study population was Population human being. All the patients were under going for extraction of impacted Horizontal mandibular third molar, who fulfilled the basic requirements of inclusion and exclusion criteria in the series of the study. 20 patients (Group-A) whose full veneer crown were prepared on Alloplastic bone substitute and another 20 patients (Group-B) whose were without alloplastic bone substitute. 20 patients were selected under this group where surgical extraction of mandibular horizontal impacted 3rd molar standard conventional method was followed by alloplastic bone substitute, Beta tricalcium phosphate. 20 patients were selected under this group where surgical extraction of mandibular horizontal impacted $3^{\text {rd }}$ molar standard conventional method was followed by alloplastic bone substitute, Beta tricalcium phosphate. Inclusion criteria were Horizontal mandibular $3^{\text {rd }}$ molar, Noninfected $3^{\text {rd }}$ molar region and Patient given consent for the study. Exclusion criteria were patients with any systemic bone diseases, medically compromised patient, alcoholics and other drug addicted people and patients who are not willing to be a part of the study. Statistical analyses of the results were obtained by using windows-based computer software devised with Statistical Packages for Social Sciences (SPSS-26). The results were presented in tables, figures, diagrams. Comparison of means made by using Student t-test and categorical data was analyze by Chi-square Test, Odds Ratio (OR) with 95\% confidence interval and $p$ value $<0.05$ was considered significant.

\section{RESULTS}

Table shows the distribution of the age of the patients. Majority of the patients 22(55.0\%) were of 1825 years age group and another $15(37.5 \%)$ were at their 26-35 age group. Mean age of the patients was $25.97 \pm 4.99$ years. Table shows the sex distribution of the patients. Among the patients $57.5 \%$ were female and rest was male. Male: female ratio was $1: 1.35$. The mean difference in the score of radiological outcomes was assessed through independent sample' $t$ ' test following Levene's test for equality of variance. No significant difference in radiological response was evident between the groups before one month $(\mathrm{P}>0.05)$. At follow up of one month to six months the difference of radiological change appeared statistically significant (P <.001). The graph illustrates the difference in radiological changes between the patients provided with alloplastic bone substitute and those not given with alloplastic bone substitute. Patients with alloplastic bone substitute showed better radiological outcome then their non-alloplastic counterparts. The difference between the two groups was ill defined in the initial few weeks but the difference stared to widen up from one month onward. In the 6 months follow up the difference became well established.

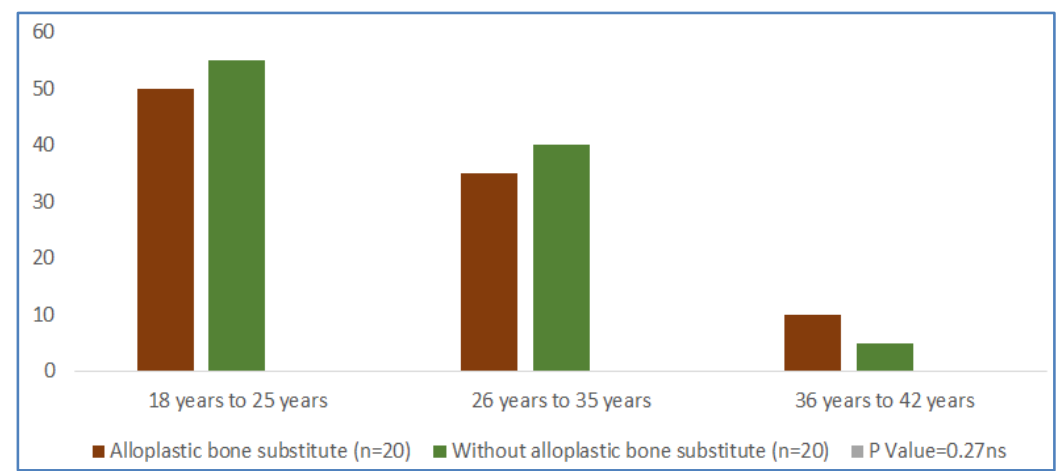

Fig-I: Age distribution of the patients in two study groups $(n=40)$ 
Table-I: Age group Mean \pm SD of the patients in two study groups $(n=40)$

\begin{tabular}{|l|l|l|}
\hline Age Group & Alloplastic bone substitute $(\mathbf{n}=\mathbf{2 0})$ & Without alloplastic bone substitute $(\mathbf{n}=\mathbf{2 0})$ \\
\hline Mean \pm SD & $25.10 \pm 4.37$ & $26.85 \pm 5.52$ \\
\hline \multicolumn{2}{|c|}{ P value performed by Independent student t-test, $\mathrm{ns}=$ Not significant } \\
\end{tabular}

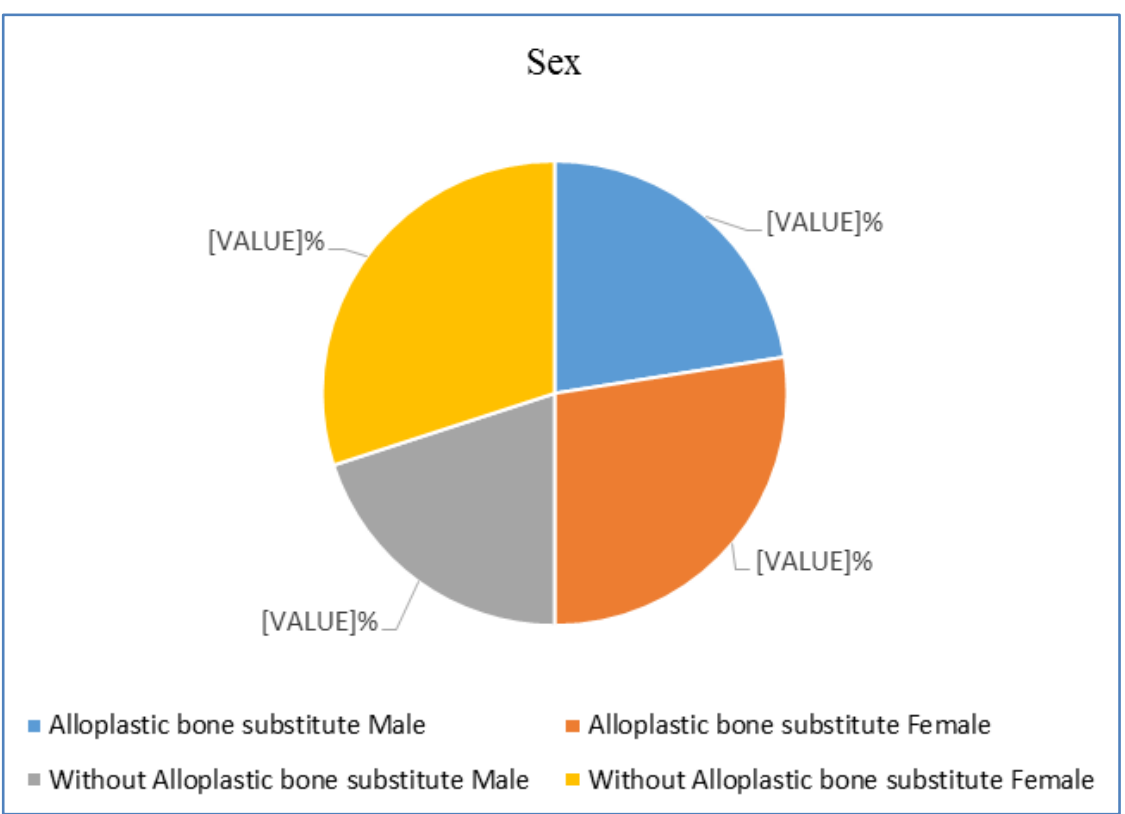

Fig-II: Sex distribution of the patients in two study group $(\mathrm{n}=40)$

Table-II: Comparison of radiological outcomes (diameter of radiolucent area) of the patients between the two management groups $(\mathrm{n}=\mathbf{4 0})$

\begin{tabular}{|l|l|l|l|l|l|}
\hline $\begin{array}{l}\text { Radiological } \\
\text { diameter }\end{array}$ & Group & N & Mean & $\begin{array}{l}\text { Std. } \\
\text { Deviation }\end{array}$ & $\begin{array}{l}\text { Std. Error } \\
\text { Mean }\end{array}$ \\
\hline $\begin{array}{l}\text { Immediate } \\
\text { after operation }\end{array}$ & Alloplastic bone substitute & 20 & 17.85 & 2.28 & 0.51 \\
\cline { 2 - 6 } & Without alloplastic bone substitute & 20 & 19.05 & 1.93 & 0.43 \\
\hline \multirow{2}{*}{ After 1 month } & Alloplastic bone substitute & 20 & 13.30 & 2.36 & 0.53 \\
\cline { 2 - 6 } & Without alloplastic bone substitute & 20 & 16.30 & 1.72 & 0.38 \\
\hline \multirow{2}{*}{ After 3 months } & Alloplastic bone substitute & 20 & 8.30 & 1.56 & 0.35 \\
\cline { 2 - 6 } & Without alloplastic bone substitute & 20 & 12.70 & 1.34 & 0.30 \\
\hline \multirow{2}{*}{ After 6 months } & Alloplastic bone substitute & 20 & 3.95 & 1.23 & 0.28 \\
\cline { 2 - 6 } & Without alloplastic bone substitute & 20 & 7.35 & 0.88 & 0.20 \\
\hline
\end{tabular}

Table-III: Independent sample test of the patients between the two management groups $(n=40)$

\begin{tabular}{|l|l|l|l|l|l|l|l|l|l|}
\hline & \multicolumn{2}{l}{$\begin{array}{l}\text { Levene's Test } \\
\text { for Equality } \\
\text { of Variances }\end{array}$} & \multicolumn{6}{l|}{ t-test for Equality of Means } \\
\hline $\begin{array}{l}\text { Radiological } \\
\text { diameter }\end{array}$ & F & Sig. & $\mathbf{t}$ & df & p value & $\begin{array}{l}\text { Mean } \\
\text { Difference }\end{array}$ & $\begin{array}{l}\text { Std. Error } \\
\text { Difference }\end{array}$ & $\begin{array}{l}\text { 95\% Confidence Interval } \\
\text { of the Difference } \\
\text { Lower }\end{array}$ \\
\hline $\begin{array}{l}\text { Immediate after } \\
\text { operation }\end{array}$ & 0.21 & 0.65 & -1.80 & 38.00 & $0.08^{\text {ns }}$ & -1.20 & 0.67 & -2.55 & 0.15 \\
\hline After 1 month & 2.39 & 0.13 & -4.59 & 38.00 & $<0.001^{*}$ & -3.00 & 0.65 & -4.32 & -1.68 \\
\hline After 3 months & 0.45 & 0.51 & -9.57 & 38.00 & $<0.001^{*}$ & -4.40 & 0.46 & -5.33 & -3.47 \\
\hline After 6 months & 1.21 & 0.28 & -10.05 & 38.00 & $<0.001^{*}$ & -3.40 & 0.34 & -4.08 & -2.72 \\
\hline
\end{tabular}

$\mathrm{p}$ value performed by Independent student t-test, $\mathrm{ns}=$ Not significant, ${ }^{*}$ Significant 


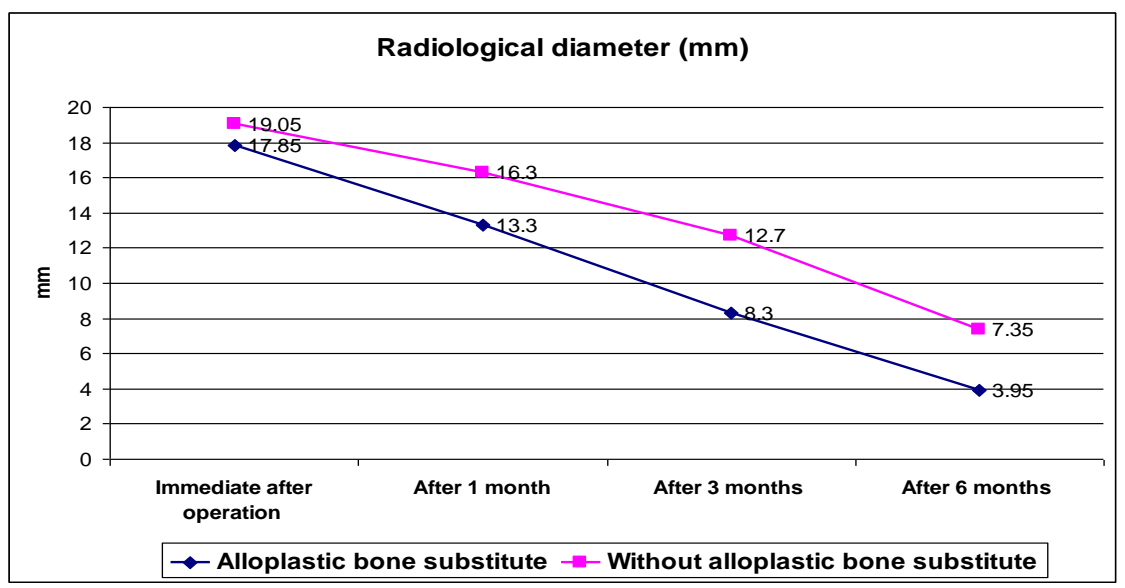

Fig-III: Radiological diagram $(\mathrm{mm})$ of the patients in two study group $(\mathrm{n}=40)$

Table-IV: Distribution of the patients by management type and history of complication

\begin{tabular}{|l|l|l|l|l|}
\hline Infection & $\begin{array}{l}\text { Alloplastic bone } \\
\text { substitute }(\mathbf{n = 2 0})\end{array}$ & $\mathbf{\%}$ & $\begin{array}{l}\text { Without alloplastic bone } \\
\text { substitute }(\mathbf{n = 2 0})\end{array}$ & \% \\
\hline Yes & 1 & 5.0 & 6 & 30.0 \\
\hline No & 19 & 14.0 & 33 & 82.5 \\
\hline Total & 20 & 100.0 & 20 & 100.0 \\
\hline Chi-square test & $\chi^{2}=4.329, \mathrm{p}=0.037, \mathrm{df}=1$ & \multicolumn{2}{|l}{} \\
\hline
\end{tabular}

\section{DISCUSSION}

There are several reasons to consider preservation of the alveolar socket immediately following tooth extraction. One reason for placing a graft of a synthetic biomaterial is to stabilize the coagulum within the socket and avoid possible reduction of the hard tissue volume required for bone regeneration [17]. Another reason for placing a graft into an extraction socket is to provide a scaffold for the in-growth of cellular and vascular components to form new bone of acceptable quality and quantity. The presented research studied 40 cases of mandibular horizontal impacted teeth to evaluate the status of bone regeneration after surgical extraction and filling the bony cavity with or without beta tricalcium phosphate. There was significant relationship in distribution of sex in impaction. The distribution of impacted third molars by sex is shown in Table-2, there was significantly more females $(56 \%)$ than males $(44 \%)$ with at least one impacted third molar [18]. In our study $57.5 \%$ of respondent were female and $42.5 \%$ were male which was similar to that. These study total 40 patients with Horizontal impaction were investigated. All the patients were categorized into three age groups, Group 1 (18-25 years), Group II (26-35 years) and Group III (36-42 years). Older age was fund to increase the risk of an extended operation time. Mean age was $25.97 \pm 4.99$ years (Table-1). Among the male population 18-25 years comprises the highest $(55.1 \%)$ subject.

Surgical removal of third molars causes significant pain, swelling, and trismus even when that is removed using a gentle surgical technique. Site and size of the bony defects has a strong relation with the outcome (bone regeneration) of treatment. Relative bigger bony cavity takes time for complete bony healing after surgical extraction but small sized bony cavity takes less time and showed uniformed bone formation. In this study the categorized our 40 cases into (less than $2 \mathrm{~cm}$ ) and (more than $2 \mathrm{~cm}$ ) sized bony cavity. Most $65.0 \%$ of our cases were less than $2 \mathrm{~cm}$ and the rest 35.0 were more $2 \mathrm{~cm}$ sized. Whereas some study showed that allograft in defects more than $3 \mathrm{~cm}$ in diameter had approximately the same rate of success as those in small defects. Bone regeneration after surgical extraction of horizontal impaction Third Molar has several influencing factors. Oral hygiene status the prime of them. Of the presented cases oral hygiene index was calculated to evaluate the oral hygiene status. These showed $42.5 \%$ of the total cases had poor oral hygiene status and $20.0 \%$ had average oral hygiene status. Outcome of the treatment of this study was evaluated on the basis of post-operative radiological diameter of the defect, radiological evidence of trabeculae formation. In this study out of 40 cases, 20 cases (study) were used beta tricalcium phosphate as bone substitute and remaining 20 cases (control) no bone substitute. Follow up was given immediate after operation, 1 month, 3 month and 6 month interval. Study cases showed mean immediate after operation diameter of bony defect was 17.85 after six months mean diameter was " 3.95 " with standard deviation "1.23" but the control cases showed immediate after operation mean diameter of 19.05 and after six month 7.35 with standard deviation 0.88 .

In this study radiological outcome was assessed through independent sample ' $t$ ' test following Levene's test for equality of variance. No significant difference in radiological response was evident between 
Muhammad Mubashirul Haque et al., Sch J Dent Sci, Jun, 2021; 8(5): 153-159

the groups before one month $(\mathrm{P}=0.08)$ at follow up of one month to six months the difference of radiological change appeared statistically significant $(P=0.00)$. It was found that reducing the diameter of lesion with allows plastic bone grafting both clinically and radio logically was better than conventional. This observation was concluded by them that the patients with alloplastic bone substitute showed better radiological outcome than their non-alloplastic bone substitute counterparts. They also revealed the outcomes between two groups were poorly defined in the initial few weeks but in the later period like one month it was significant, which results is very close to [19].

In this study trabecular pattern was assessed through independent sample ' $t$ ' test following Levene's test for equality of variance. Significant difference in radiological response was evident between the groups. From immediate after operation to six months the difference of trabecular pattern appeared to be statistically significant. $(\mathrm{P}=0.25) \&(\mathrm{P}=0.00)$. Patients with alloplastic bone substitute showed superior trabecular pattern that the non-alloplastic bone substitute counterparts. The difference of trabecular pattern between the two groups started to amplify in the post-operative period. The difference was persistent throughout the period 6 months with gradual increasing tendency. Presence or absence of post-operative infection indicates failure or success of bone substitute. In this study $82.5 \%$ study cases showed no infection but control group showed $17.5 \%$ infection. That is rate of infection found to be lower in the study group (Table-7) $\mathrm{x}^{2}=4.329 \mathrm{p}=0.037 \mathrm{df}=1$. Correlation of oral hygiene status and post-operative complication was done. This showed $82.5 \%$ had no post-operative infection but $17.5 \%$ had post-operative infection. All of them were of poor oral hygiene status (Table-3) which is supported by the findings [20]. Infection occurred usually within the one week after operation and presented by the features of localized swelling and exudation which leads to exposure of grafted bone substitute. This condition was then treated by removal of the graft material and curettage of necrosed tissue and use of proper antibiotics.

\section{CONCLUSION}

Both QDSR and LRA methods can be used in evaluation of the rate of bone formation in the tooth socket but the former method is more accurate.

\section{Limitations of the study}

This was a single center study with limited sample size. So, the result might not be reflecting the scenarios of the whole country,

\section{RECOMMENDATION}

Antibiotic uses in Bangladesh are very crucial at present. Government should give attention to the outpatient department were Third Molar Sockets Augmented not using Beta Tricalcium Phosphate. Study also recommends multi-Centre study with large sample size.

\section{REFERENCES}

1. Herman H, De Boer. 'The history of bone grafts' Clin ortho Relt Res. 1988; 226: 292-98.

2. Albee FH, Morrison HF. 'Studies in bone growth: tricalcium phosphate as a stimulus to osteogenesis', Ann Surg. 1920; 71: 32-39.

3. Zhang Y, Xu HH, Takagi S, Chow L. ' In-situ hardening hydroxyapatite-based scaffold for bone repair' , J Mater Sei mater Med. 2006; 17: 43744445.

4. Palm FC Hilscher and Kind M. 'Einsatz einer neuen synthetischen, phasenreinen beta-TCP Keramilk in der Mund-, Kiefer- und Gesichtschirurgie', Implantologie Journal. 2006; 10: 4.

5. Horch HHR, Sader C, Pautke A, Neff HD and Kolk A. 'Synthetic, pure phasebeta tricalcium phosphate ceramic granules (cerasorb) for bone regeneraton in the reconstructive surgery of the jaws', Int J oral Maxillofac Surg. 2006; 35, 8: 708 13.

6. Palti.'A concept for the treatment of various Dental bone defects Implant Dent. 2002; 11(1): 73-8.

7. Foitzik $\mathrm{C}$ and Stamm M. Einsatz von phasenreinem beta-Trical cium phosphate zur Auffullung von ossaren Defekten-Biologische Materialvorteile und klinische Efrahrungen',Quintessenz. 1997; 48: 1365-1377.

8. Foitzik $\mathrm{C}$ and Staus H. 'Pure beta trical cium phosphate bone substitution in periodonatal disease', Quintessenz. 1999; 50(10): 1049-1058.

9. Bokan I, Bill JS, Schlagenhauf U. Primary flap closure combined with Emdogain $\AA$ alone or Emdogain $\AA$ and Cerasorb ${ }^{\circledR}$ in the treatment of intra- bony defects. Journal of clinical periodontology. $2006 \mathrm{Dec} ; 33(12): 885-93$.

10. Reinhardt $\mathrm{C}$ and Kreusser B. 'Retropektive Studie nach Implantion mit Sinuslift and CerasorbAugmentation', Dent Implanto. 2002; 4: 18-26.

11. Kreusser B. Good results even without adding autolotous cancellous bone' DZW.1998; 12.

12. Zerbo.'Histology of Human alveolar bone regeneration with a porous tricalcium phosphate. A report of two cases Clin Oral implants Res. 2001; 12(4): 379-84.

13. Zerbo IR, Bronckers AL, De Lange G, Burger EH. Localisation of osteogenic and osteoclastic cells in porous $\beta$-tricalcium phosphate particles used for human maxillary sinus floor elevation. Biomaterials. 2005 Apr 1;26(12):1445-51.

14. Fugazzotto PA, Shanaman R, Manos T, Shectman R. Guided bone regeneration around titanium implants: report of the treatment of 1,503 sites with clinical reentries. International Journal of Periodontics \& Restorative Dentistry. 1997 Jun $1 ; 17(3)$. 
15. Antoun H, Bouk H, Ameur G. Bilateral sinus graft with either bovine hydroxyapatite or $\beta$ tricalcium phosphate, in combination with platelet-rich plasma: A Case Report. Implant dentistry. 2008 Sep 1;17(3):350-9.

16. Yassibag- Berkman Z, Tuncer O, Subasioglu T, Kantarci A. Combined use of platelet- rich plasma and bone grafting with or without guided tissue regeneration in the treatment of anterior interproximal defects. Journal of periodontology. 2007 May;78(5):801-9.

17. Chen ST, Wilson Jr TG, Hammerle $\mathrm{CH}$. Immediate or early placement of implants following tooth extraction: review of biologic basis, clinical procedures, and outcomes. Int J Oral Maxillofac Implants. 2004 Jan 1;19(Suppl):12-25.

18. Quek SL, Tay CK, Tay KH, Toh SL, Lim KC. Pattern of third molar impaction in a Singapore
Chinese population: a retrospective radiographic survey. International journal of oral and maxillofacial surgery. 2003 Jan 1;32(5):548-52.

19. Schwartz Z, Mellonig JT, Carnes Jr DL, De La Fontaine J, Cochran DL, Dean DD, Boyan BD. Ability of commercial demineralized freeze- dried bone allograft to induce new bone formation. Journal of periodontology. 1996 Sep;67(9):91826.

20. Pruss A, Seibold M, Benedix F, Frommelt L, von Garrel T, Gürtler L, Dörffel Y, Pauli G, Göbel UB. Validation of the 'Marburg bone bank system'for thermodisinfection of allogenic femoral head transplants using selected bacteria, fungi, and spores. Biologicals. 2003 Dec 1;31(4):287-94. 